\title{
PLANNING FOR SUSTAINED YIELD OPERATIONS ${ }^{1}$

\author{
By G. AMIDON 2
}

\author{
G. B. $A M I D O N$
}

George Amidon graduated from the University of Minnesota Forestry College in 1936. He spent about three years with the U.S. Forest Service as a timber estimator and forest economist, seven years with the Minnesota Division of Forestry as a timber appraiser and eight years, or since 1944, with the Minnesota and Ontario Paper Company as Director of the forest management program.

\section{ABSTRACT}

Sustained yield management as applied to operations of the Minnesota and Ontario Paper Company means continuous production and balancing cut and growth by species and individual cutting unit as soon as possible, usually no longer than ten years.

The farm woodlot type of operation is considered ideal from the standpoint of growing the maximum wood because of permanency and accessibility. With this type of an operation it is estimated that present growth rates can be increased over three times and that the mean annual increment for large areas of productive forest lands, even in the comparatively slow growing timber types in Minnesota and Ontario, will reach nearly one-balf cord per acre annually.

One of the most difficult problems in the establisbment of small sustained yield units, or for that matter placing any unmanaged forest under management, is the preponderance of mature and overmature wood. However, at the expense of bolding wood well beyond its peak in growth and a possible loss in volume, the cut for all units is beld down in the interest of continuous operations and to avoid the necessity of abandoning camp and road improvements. This is done so as to convert as rapidly as possible to a balanced distribution of ages in each cutting unit.

Lower cost wood is the principal advantage of this type of planning. It may take some time before the potential value of sustained yteld cutting is fully realized, but on the premise that wood will be more valuable in the future, and all recent trends support this view, the eventual advantage to those mills starting now to grow the maximum volume of bigh quality wood close to their mills cannot be doubted.

\footnotetext{
1 Paper given at the Forest Management Session o: the joint CIF-SAF Meeting in Montreai, November, 1952.

2 Minnesota and Ontario Paper Company, International Falls.
} 


\section{INTRODUCTION}

The terms "selective cutting" and "sustained yield management" are sometimes used very loosely and their real meanings are often lost in arguments over who is or is not doing a good job of managing forest lands. For this reason it seems important to spend a few minutes at the start of this discussion in defining exactly what is meant by the term "sustained yield" as used in this paper.

The Society of American Foresters' book "Forest Terminology" defines sustained yield as applied to policy or plan of forest management as follows: "(It) implies continuous production with the aim of achieving, at the earliest practicable time, an approximate balance between net growth and harvest, either by annual or somewhat longer periods." This is a good brief definition, but it is still quite general and the difficulty of being specific and still brief is probably one of the reasons why it is often used incorrectly and why it means different things to different people.

For example, nothing is said about a balance of cut and growth by tree species or management units. Consequently you can still have sustained yield, according to the above definition, even though the more valuable wood is being cut much faster than it is growing and the less valuable wood correspondingly slower. You can also have sustained yield if one section of the forest area is being heavily overcut and the remainder of the area correspondingly undercut.

It should be evident that a cutting plan which permits overcutting of one species or one area and undercutting of other species or other areas is not good management even though cut is in balance with growth for all species over the entire area. Such a plan means trouble in the years ahead for the forest manager. Therefore, sustained yield management, as broadly defined above, does not necessarily mean good management.

Use of the term sustained yield in forestry implies, however, that the ultimate in good forestry has been achieved. As previously noted, this is not necessarily so and, consequently, the definition should be more specific if it is to mean what most people seem to think it means. Therefore, I suggest that the definition be changed as follows: "(It)-implies continuous production with the aim of achieving, at the earliest practicable time, an approximate balance, by species and management unit, between net growth and harvest either by annual or somewhat longer periods."

There may be other changes which might improve this definition, but this does seem to more clearly define our understanding of the term.

We believe further that the size of the unit is the key to the problem of growing the most wood and that really intensive management requires sustained yield cutting plans for each individual operation. The most desirable size of operation depends upon a number of factors, but it may be 
helpful to an understanding of this discussion if we consider the area most desirable from the standpoint of growing the maximum wood.

The most intensive forestry can be practiced on farm woodlots. This is seldom the case, but the opportunity is there nevertheless. The reason for this is that the farmer has long term cutting rights, and he can gradually road the area and make all of the timber readily accessible. He can do the work at his convenience, and because the area is small and well roaded it is economically possible for him to cover a large part of the woodlot each year and remove trees on the basis of age, condition and stand density. If trees blow down or become infested with insects, they are easy to salvage because the farmer is always there and the timber can be reached without added expense for new roads.

It is believed that this type of management can increase present growth rates by three times or more and that the sustained growth for large areas of productive forest land, even in the comparatively slow growing timber types in Minnesota and Ontario, can reach $1 / 2$ cord per acre annually. There are two main reasons why it is possible to manage farm woodlots intensively. These are (1) permanency of operation and (2) development of a network of roads. Therefore, if other operations can be established on the same permanent basis, greatly increased yields are possible.

This is the thinking of our Company and as a result our operations are being patterned, as nearly as possible, after this farm woodlot type of operation. The size of these cutting units depends upon existing transportation facilities, type, age and condition of the timber and available labor supply. As we have presently worked this out, our cutting units vary from 500 acres for a small settler operation to about 60,000 acres for our larger camp operations.

A discussion of the procedure followed in the development of these cutting plans, the number and type presently in operation, detailed data for a few representative cutting units and some of the problems and advantages involved in this type of planning are covered in the remainder of this report.

\section{Development of Cutting Plans}

Mills of the Minnesota and Ontario Paper Company are located at Kenora and Fort Frances, Ontario, and International Falls, Minnesota. They consist of both ground-wood and chemical plants and manufacture a wide variety of products from newsprint to the higher grades of publication papers, as well as Insulite, an insulation structural board. We use over $1 / 2$ million cords of wood per year consisting mainly of spruce, balsam, jack pine, and poplar or aspen.

At present growth rates we require all of the annual growth on a gross forest area of about 5,000,000 acres. This is 2 to 3 times as much land as needed to grow our annual needs on an area intensively managed. Our 
objective, therefore, is to concentrate our management efforts on forest lands close to our mills so that in the future our needs can be grown on the smallest possible acreage and in closest proximity to the mills.

This points up the problem. Before discussing our program for solving this problem, however, it will probably be helpful to an understanding of this paper if a few of the pertinent facts regarding the supply situation in the area where we operate are noted.

First of all, $75 \%$ of the forest land in our immediate Minnesota operating area is in public ownership (State, County and Federal), and over $90 \%$ is owned by the Crown in the Canadian areas where we obtain most of our wood. It is evident, therefore, that we are dependent to a large extent upon public agencies for our supply of raw material, that there are certain definite limitations upon what we can and cannot do in the development of a forestry program and that our forestry work must be closely coordinated with the Government's program.

The second point which has a bearing on this problem is the shortage of spruce and surplus of poplar in Minnesota and the present surplus of poplar and jack pine on our Canadian areas. This means that either mill needs in Minnesota must eventually be changed to conform to the quantities of the different woods available in our permanent supply area or the lands now growing species which are in surplus supply converted to the kind of trees which are in short supply. It is important that this problem be recognized far enough in advance so that the necessary changes can be made before it is too late.

In our Canadian areas a large percentage of the forest area contains mature and overmature wood and, therefore, the present surplus is for the most part of a temporary nature. The problem here is to convert gradually the timber types into a more balanced distribution of age classes. This is also a problem in Minnesota, but to a lesser degree.

These facts of shortages and surpluses and the unbalanced distribution of age classes were brought out in the inventory survey made of the various management districts within our operating area in cooperation with the different governmental agencies. These management districts were established prior to the survey. The initial inventory survey provided the basic information needed to start sustained yield management for the district as a whole. It indicated the areas in greatest need of attention, how much timber should be cut during the first stage of management, how the area could be broken down into cutting units, and the cut by species which the entire area could probably sustain. It did not, however, provide sufficient detail for the development of detailed operating plans. 
Operating cruises were necessary for this more detailed planning and these were made of each of the preliminary units established from the initial survey. After completion of the more detailed cruise, each cutting unit was finally established and a five-year operating plan developed. Wherever possible, each cutting unit has been established as a permanent cutting area for one type of operation and the allowable cut based upon the productive capacity of the area. In many areas the older ages predominate and this has been taken into account in setting up the allowable cut. However, major emphasis has been upon keeping the initial cut low enough so that there will always be sufficient timber in the area to justify an economic and continuous operation.

As noted earlier, these cutting units vary in size from about 500 acres to 60,000 acres. The size of the unit depends upon the type of operation which seems most adaptable to the area in question, and this is determined largely by the existing roads, water routes, etc. Areas close to main roads lend themselves best to smaller settler type operations whereas more inaccessible areas are better adapted to larger camp type operations. This is our basis for deciding upon the size and type of cutting unit, but regardless of this variation, detailed five-year cutting plans have or will be prepared for each one of these units and wherever possible each one is established as a separate sustained yield unit.

\section{SUSTAINED YIELD UNITS}

In Minnesota our most important supply area has been broken down into five management districts, and in Canada we have four pulpwood concessions, each one corresponding to a management district. After the initial survey previously discussed, each one of these districts was divided into cutting units. This work is not yet complete, but a good start has been made.

In Minnesota about 30 sustained yield units have already been established and our present estimate is that this is about one-half the number that can be developed. These vary in size from about 500 acres to 40,000 acres and the annual cut for the first period of management varies from 50 cords to 7,000 cords. About one-half of the 30 units are settler operations, and the remainder is handled by small contractors. The average annual cut for the settler operations is 400 cords and for the contractor operations 3,000 cords. These sustained units supply, at the present time, about 50,000 cords per year or $20 \%$ of our Minnesota needs.

In Canada our limit wood is cut by small contractors and Company camps. Five year operating plans have been completed or are nearly complete for about two-thirds of the concession areas. To date, 22 sustained yield cutting units have been established and these vary in size from about 20,000 acres to 60,000 acres. The average size is 36,000 acres. The annual cut for the first period varies from 2,500 cords to 20,000 cords and the 
average is 7,800 cords. A total of about 170,000 cords of wood annually or $50 \%$ of our Canadian production comes from these sustained yield units.

\section{Detail of a Few Representative Cutting Areas}

So far in this discussion we have noted that our company uses in excess of 500,000 cords of pulpwood annually, that about 50 sustained yield cutting units have been established and that these cutting units will supply about 220,000 cords of wood yearly, or roughly, $40 \%$ of our present needs. When our cutting plans are all complete, it is estimated that we will obtain about $50 \%$ of our total needs from areas established on a sustained yield basis.

Before discussing some of our specific cutting areas a few points should be noted as follows. First of all, in Canada we have long term cutting rights and are requested by the Government to develop cutting plans, although the exact type is not specified. In Minnesota the company owns the fee to fairly large blocks of timberland, but over one-half the land within our cutting areas is under state control and the company can obtain only short term cutting rights on these lands. Therefore, in developing these plans in Minnesota it is necessary that they be closely coordinated with the State's plans, but this is complicated by the fact that the State sells most of its timber at auction sales on two year permits. Consequently, it is difficult for the company to make definite long term plans in areas where it does not control sufficient timber to justify development of these areas. Because of the limited contract period for State timber, many timbered areas are not being developed as fast as they should be in order to obtain maximum yields.

In spite of this handicap, however, the company has gone ahead with its planning and taken the chance that it will obtain most of the State timber within the cutting areas in cases where it has sufficient timber of its own to justify the major part of the development cost.

These permanent cutting areas can be broadly classified into three types: (1) small settler operations, (2) medium sized contractor operations (3) larger sized company camp operations. These different classes vary only in amount of wood produced and number of men employed, but they are all established for continuous production and patterned after the farmer woodlot type of operation. In the settler operation the area is set aside for a farmer, preferably one living near the area, and he commutes back and forth from his farm. In the contractor and camp operation a camp is usually centrally and permanently located and the workers travel by car, truck or bus, or they walk if the distance is not too great, to and from the cutting area. In areas where road building is difficult and expensive the camps are more portable and will be moved at about 10 year intervals. 
Example of a few of these classes of operations are covered in the following paragraphs:

\section{Small Settler Operations}

One of our small settler operations is located along State Highway No. 11 about 20 miles southwest of International Falls. The company owns a contiguous block of timber here about 1,200 acres in size which has been set aside as an experimental forest. It has also been set aside as a farm woodlot for a local resident who lives within two miles of the area with the understanding that he can have whatever off-season employment is available in the form of harvest and improvement cuttings, disking, planting and other silvicultural jobs.

This settler and his son are now starting their fourth season of work on the area. Because the main roads were in and the company tapped the area in several places with logging roads, the settler did not have to make any appreciable investment in equipment. $\mathrm{He}$ uses a power saw for cutting, a small tractor for skidding and bob-tail truck for hauling.

The total merchantable timber on this area is about 13,000 cords of pulpwood and 1,400,000 feet of hardwood sawlogs. The merchantable types average 16.3 cords per acre and 1,400 feet of sawtimber. About 5,000 cords of the pulpwood is in the mature and overmature classes and the cutting plan calls for a higher cut during the first stages of management than the area can permanently sustain in order to salvage as much of the older wood as possible before it deteriorates further. Consequently, the cut for the first five years was set up at about 600 cords annually. For the second five years this will be reduced to about 400 cords annually and this is considered about the sustained cut for the area. However, it may be necessary to reduce this somewhat after the ten years to permit the young stock to build up before the estimated future cut of 400 cords can be sustained.

During the first five years the plan is to cover the area as completely as possible removing those trees which are oldest and deteriorating most rapidly. This would be considered a very costly operation except for the fact that the operation is a permanent one, the main roads are in and the cost of the logging roads can be spread over a long period and, as a result, a large volume of wood.

One of the major problems in maintaining the maximum productive capacity of any area is the establishment of a new crop of timber after the old one has been removed. In this particular area all of the old cut-over areas which did not restock naturally are being planted, but in the future it is expected that through careful cutting a new stand will become established before the old crop is entirely removed.

This type of operation is considered desirable for both the operator and the company because it assures him of permanent employment near 
home in his off season and it assures the company maximum yields and a dependable labor supply, the two most vital factors in providing the mill with its raw material.

\section{Medium Sized Contractor Operations}

Another example of this type of operation, except on a somewhat larger scale, is an area of 23,000 acres located 40 miles southeast of International Falls, 10 miles from a main state road. This area was established four years ago and has been operated every year since then by a company contractor. The company owns about one-half the land in this area on which there is an estimated 70,000 cords of pulpwood. Most of the remainder of the area is State land on which there is also about 70,000 cords of pulpwood, making a total of 140,000 cords for the unit.

In the development of this area about 10 miles of main road was constructed or improved and a modern camp built in a central location as a permanent establishment. Expenditures totaled about $\$ 80,000$ the first year for the main road, camp and winter haul road. The road system is being extended each year, and within a short time all of the timber types will be readily accessible, and, as in the farm woodlot, trees can then be cut on the basis of age and condition, damaged timber can be salvaged, and the area managed intensively for maximum yield.

This large initial investment could not have been justified except for the fact that the company owned a large block of timber in the area. We expect to buy the State timber in this area also, but, as previously noted, this, at present, can only be purchased on short term contracts. Because of this large block of timber in company ownership, it was easier to plan for permanent operations and the camp constructed built on a more permanent basis. The camp cost over $\$ 50,000$ and is considered one of the best and most modern in this entire area. The operation is planned for about 10 months each year, and this steady employment plus good living conditions assures a good supply of labor as well as maximum yields.

One of the greatest difficulties in establishing continuous operations in most of our cutting units is the preponderance of mature and overmature wood. This area is no exception, with about $60 \%$ in these two classes or approximately 85,000 cords. Because of this it is necessary to cut more than the area will sustain during the first stages of management in order to salvage as much of the old timber as possible. In this particular area the plans calls for cutting about 7,000 cords annually during the first 10 years or until most of the mature wood has been cut. After that the cut will be reduced to what the area will permanently sustain and at present it is estimated that growth will amount to about 5,000 cords per year or about one-quarter of a cord per acre annually for the productive area. 
Cutting plans for the other areas established for sustained yield are all much the same as the two explained in the preceding paragraphs, except in Canada the development cost is much greater, but so is the volume and the cut for each operation is somewhat higher. However, for most units the annual cut is between 6,000 and 10,000 cords. The problems vary with the extent of control of the lands by the company, the accessibility of the areas, and the distribution of age classes, but in all cases adjustments are made with the aim of insuring continuous production and maximum yield.

\section{The Problem of Too Much Old Wood}

As previously noted, one of the most difficult problems in the establishment of small sustained yield units is the preponderance of mature and overmature wood. When this old wood consists of poplar or jack pine the problem is more acute because of the rapid rate of deterioration of these two species after they reach maturity.

In each unit where this situation exists, and it exists to a greater or less degree in most areas when they are first placed under management, the question as to why all of the old timber should not be cut as fast as possible is raised every time this matter is discussed. This questioning is not limited to only those in management who are primarily concerned with costs and naturally wonder about the wisdom of developing new units before the old timber is cut out in the units already developed, but it is also a matter of considerable disagreement among foresters. For this reason, and because the maintenance of a fairly uniform and continuous cut in each sustained yield unit is of major importance to the success of small permanent operations, I would like to spend a few minutes discussing why prolonging the cut of this old timber is considered necessary in the initial stages of management and why it will cost no more in the long run than heavier cutting over a shorter period of time.

In analyzing this problem there are two basic facts that must be known, (1) whether or not the species in question is in surplus or short supply and (2) the rate of deterioration after the stand has reached its peak in growth.

In our general area both jack pine and poplar are growing faster than they are being cut. They both reach their peak in mean annual increment at about 50 years on an average site, and mortality starts to exceed growth after 80 years. Spruce, on the other hand, is in short supply, reaches its peak in growth at about 100 years, but mortality does not exceed growth until after 150 or 160 years. This means that 100 year old spruce can be held for 50 or 60 years before any appreciable loss in volume occurs and that 50-year old poplar and jack pine can be held for about 30 years before mortality exceeds growth.

With these facts in mind let's consider again the small contractor 
operation previously discussed. The allowable annual cut established for this area was 7,000 cords for the first ten years. The area contains about 85,000 cords of overmature wood, mostly poplar and jack pine. This timber is presently about 75 years of age and there will probably be a loss in net volume after it exceeds 80 years. Therefore, instead of cutting only 35,000 cords for the first five years why not cut the 85,000 cords of mature wood? This would require an annual cut of 17,000 ocrds per year or 10,000 cords more than planned.

First of all, it should be remembered that there is an oversupply of these two species and if more wood is cut in this particular area less wood will have to be cut in some other unit. Consequently, as there is overmature wood in most of the units, it makes no difference insofar as loss in volume is concerned whether the poplar and jack pine required is all taken from one area or a number of areas.

On the other hand, if this area were cut at the rate of 17,000 cords per year for five years it would then be necessary to reduce the cut to about 2,000 cords per year during the period required for the younger timber to grow to maturity. This low a cut would not be an economic operation in this area and, consequently, the camp and roads would have to be abandoned for 50 years or more and by then the area would be in the same condition that it is in now with too much old wood. This practice, therefore, works against maximum yield and encourages a system whereby the forest areas would never have a balanced distribution of ages or provide high quality wood.

Because spruce maintains its volume for 50 to 60 year after reaching maturity, no loss in volume is incurred if the cut of this species is prolonged over a long period of time. Therefore, in the interest of permanent operations, maximum yield and high quality wood, it seems desirable to maintain the cut of this species at about the rate the unit can continuously sustain.

This is now our Company's policy and all of our areas will be developed in this manner as rapidly as possible so long as economic conditions are such that we have the capital to expend for the major development work required in opening up new areas.

\section{Advantages of Sustained Yield Units}

What are the advantages of this kind of a program? It is, of course, extremely difficult in these times to attempt to say with assurance what may develop many years in the future. However, it seems as certain as anything can be that the great forests of the United States and Canada will increase in value more rapidly in the future than they have in the past and become of even greater significance to the economy of our respective nations and the world. You do not have to be an expert with a "crystal ball" or even have an unusual amount of imagination to predict that the 
forests of North America, which comprise about one-fifth of the total forest area of the world and contribute nearly $70 \%$ of all wood pulp produced in the world, will be of ever increasing value if they are properly managed. Futher evidence of this is the expert opinion that we are barely into the coming age of wood and that wood chemistry is little more than an infant in the industrial revolution that has transformed the lives and thoughts of people throughout the world.

If this is not too optimistic a picture, and many world experts have testified that it is not, then it can be said with great certainly that forest areas now being managed for sustained yield, areas where the growing stock is building, where maximum yield and high quality wood are the conscious foundations of management's policy, are areas which will pay tremendous dividends in terms of low cost wood in the years to come. Whether this great potential value will be realized 10 years or 25 years from now may be open to argument, but there should be no argument about the eventual end result.

The number one advantage of planning for sustained yield is, therefore, lower cost wood in the long run. Before leaving this point, just a word about the term "long run". Many people feel that any period beyond five years is long, but in the life of a tree or a million dollar pulp mill it is very short. The major reason why there has been such a spurt in industrial forestry within the past few years is because of the recognition that high cost pulpwood manufacturing facilities cannot be moved when the supply of raw material gives out and, therefore, a sustained supply of wood is essential to sound financing. For this reason it is of great importance to plan for an assured supply of wood for not only the next 15 or 25 years, but the next 50 or even 100 years. The mill that gives realistic recognition to the future will have a tremendous advantage over those mills that hope the supply will take care of itself.

Lower cost wood is the ultimate goal of this type of planning, but what are the factors that will tend to lower costs? The major ones compared to the system of large camps of short duration are listed below:

1. The cost per cord of major development items such as camps, roads and river improvements will be less because these facilities will be of permanent use and will, in the long run, service a large volume of wood.

2. Better planning is possible in an area established as a continuous cutting unit. The complete road system can be laid out so that each piece of road will serve the maximum volume of wood. Equipment needs can be better determined by an operator that knows where he is going to operate and the approximate size of the job several years in advance.

3. After the major development work is complete, annual expenditures for extensions, maintenance and improvement of these permanent facilities will be much lower and more uniform as contrasted to the old 
"cut and move" system where large expenditures must be made every few years forever for new camps, main roads, etc. However, after these permanent units are all established, it will be possible to curtail all development expense if necessary during periods when mill needs are small because road systems will be built ahead of operations and the required mill needs can be obtained from the areas already developed.

4. A more stable and dependable labor force can be developed on this type of an operation. This will result in less turnover and higher production per man day and, as a result, less camp overhead expense per cord of wood produced.

5. Higher quality wood and much greater yields per acre will be obtained in the long run. Eventually each one of these units will have a balanced distribution of age classes and trees can be cut when they reach their peak in growth, but before they start to deteriorate. This, in itself, will greatly increase yields but, in addition more thinning and salvage cutting will be economically feasible in this type of operation and further increase growth rates and total useable volume. As a result, less wood will have to be obtained from high cost freight areas long distances from the mill. In addition, the supply from these areas will be more secure.

There are, of course, some immediate disadvantages to this type of operation such as the higher cost of going longer distances to and from work, increased road maintenance and snow plowing and more careful and, therefore, more costly cutting. These, however, are considered insignificant in balancing them against the many real advantages of permanent operations.

\section{SUMMARY}

This is a summary of the major points covered in each section of the report.

Sustained yield management, as applied to our operations, means continuous production and balancing cut and growth by species and individual cutting unit as soon as possible, usually no longer than ten years.

The farm woodlot type of operation is considered an ideal from the standpoint of growing the maximum wood because of their permanency and accessibility. With this type of an operation it is estimated that present growth rates can be increased 3 to 4 times and that the mean annual increment for large areas of productive forest lands can, even in the comparatively slow growing timber types in Minnesota and Ontario, reach nearly one-half cord per acre annually. Therefore, the operations of our Company are being patterned, as nearly as possible, after this farm woodlot type of operation. 


\section{Development of Cutting Plans}

The Company's permanent supply area has been broken down into five management districts in Minnesota and four in Canada, and inventory surveys were made of each of these areas in coperation with the State and Provincial Governments. This data served as a guide to improved management until more detailed operating surveys could be made. The initial survey indicated the areas in greatest need of attention, general condition of the timber, the volume and kinds of wood that should be cut during the first stages of management and an indication of the sustained capacity of the land.

After this phase of the job was complete, the districts were tentatively divided into cutting units, the size depending upon the accessibility of the area. Detailed operating cruises were then made of these areas, their boundaries finally established and five year cutting plans developed. The allowable cut for the five years was established taking into consideration the condition of the wood, but placing major emphasis on keeping the cut low enough so that the operation could be made permanent.

\section{Sustained Yield Units}

To the present time 50 of these sustained yield units have been established - 30 in Minnesota and 22 in Canada. They vary in size from 500 acres for a settler operation to 60,000 acres for a large Company camp operation. The allowable annual cut varies from 50 cords to 7,000 cords per unit in Minnesota and from 2,500 cords to 20,000 cords in Canada. The 50 units will support a cut of about 220,000 cords yearly or roughly $40 \%$ of our present needs. Eventually we expect to have enough of these units to supply about one-half of our requirements.

\section{Representative Areas}

These cutting units are divided into three types of operations (1) small settler operation, (2) medium sized contractor operation and (3) larger sized Company camp operation. The different classes vary only in the amount of wood produced and number of men employed, but they are all established for continuous production.

One of our small settler operations covers an area of 1,200 acres which has been set aside as a farm woodlot for a settler that lives nearby and drives back and forth to work. $\mathrm{He}$ and his son are now on their fourth season cutting about 600 cords annually, the allowable cut for the first five years. The sustained cut for this area is estimated at 400 cords per year, but about 5,000 cords is mature and overmature and this timber will be cut during the first 10 years and then the cut reduced.

A second area is 23,000 acres in size and has been set aside for a small contractor. Here there are 140,000 cords of wood, of which about 85,000 cords is mature and overmature. The allowable cut for the first 
10 years, or until the old timber is cut, will average about 7,000 cords per year and then the cut will be reduced to the sustained growth or about 5,000 cords annually.

\section{Problem of Old Wood}

One of the most difficult problems in the establishment of small sustained yield units, or for that matter placing any unmanaged forest under management, is the preponderance of mature and overmature wood. However, at the expense of holding wood well beyond its peak in growth and a possible loss in volume, the cut for all of our units is held down in the interest of continuous operations and to avoid the necessity of abandoning camp and road improvements. This is done so as to convert as rapidly as possible to a balanced distribution of ages in each cutting unit.

\section{Advantages}

Lower cost wood is the principal advantage of this type of planning. It may take some time before the potential value of sustained yield cutting is fully realized, but on the premise that wood will be more valuable in the future, and all trends support this view, the eventual advantage to those mills starting now to grow the maximum volume of high quality wood close to their mills cannot be doubted. 